lower than ours whereas at the other temperatures they are higher, the discrepancy at $75^{\circ} \mathrm{C}$ and $10,000 \mathrm{~kg} / \mathrm{cm}^{2}$ being as large as 25 per cent. The agreement with low-pressure data $^{3-6}$ is generally good and within the experimental error of our observations, which is estimated to be \pm 1 per cent. Interpolation of our results shows that the temperature at which the initial pressure coefficient is zero is $33 \cdot 5^{\circ} \mathrm{C}$. Values of the absolute viscosity of water given in Fig. 2 have been calculated from our results with the aid of Bingham and Jackson's results for the viscosity of water at atmospheric pressure ${ }^{7}$.

We thank the Council for Scientific and Industrial Researeh for providing funds to enable us to build the high-pressure viscometer.

K. E. Betr

J. B. CAPPI*

Department of Chemical Engineering and Chemical Technology,

Imperial College of Science and Technology, London, S.W.7.

* Present address: E. I. Du Pont de Nemours Co., Seaford, Delaware. ' Cappi, J. B., Ph.D. thesis, Univ. London (1964).

${ }^{2}$ Bridgman, P. W., Proc. Amer. Acad. Arts Sci., 61, 57 (1926).

${ }^{3}$ Cohen, R., Beibl. Ann. Phys., 45, 666 (1892).

- Hauser, L., Ann. Phys., 5, 597 (1901).

'Mozynski, J. R., Trans. Amer. Soc. Mech. Eng., 83 C, 111 (1961).

- Weber, W., Z. Angew. Phys., 15, 342 (1963).

'Bingham, E. C., and Jackson, R. F., Bull. Nat. Bur. Stand. (U.S.), 14, 75 (1918).

\section{Calculations with Two Nearly Equal Quantities}

A FAMILIAR experimental problem arises when two quantities of about equal magnitude are measured, and a third quantity equal to the difference between the two is to be calculated. The relative error in the calculated result can be intolerably high. An example of such a situation is the measurement of airglow radiations from the upper atmosphere in the presence of Rayleigh scattering from the lower atmosphere, where the strength of the desired signal may be small compared with that of the background. Initial measurements of airglow which we made with a simple photometer resulted in plots of calculated airglow intensity versus time with such large fluctuations that no interpretation was possible.

In these circumstances, information can be extracted with greater reliability by taking ratios rather than differences. Taking the example referred to here, let the intensity of the background be $B$, and that of the signalplus-background be $S+B$. If each is measured by counting the total number of photons arriving in a stand. ard time-interval, then the standard deviations, $E_{B}$ and

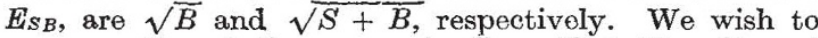
compare the relative errors in $S=(S+B)-B$, and $R=(S+B) / B$, denoted by $e_{S}$ and $e_{R}$, respectively. It is easily shown that in the situation being considered:

$$
\begin{aligned}
e_{S} & =\sqrt{\frac{S+2 B}{S^{2}}} \\
e_{R} & =\sqrt{\frac{S+2 B}{B(S+B)}, \text { and }} \\
\frac{e_{B}}{e_{R}} & =\sqrt{\frac{B(S+B)}{S^{2}}}
\end{aligned}
$$

It is of interest to note that while the accuracies of both $S$ and $R$ can be improved by increasing the counting time, the ratio of these accuracies is independent of counting time.

A plot of $\left(e_{S} / e_{R}\right)$ versus $R$ is shown in Fig. 1. The ratio of errors has the value unity at $R=2 \cdot 6$, or $S=1.6 B$. For $S<1.6 B$, the advantage lies with taking the ratio. This is consistent with my finding that plots of $R$ calculated from my data had considerably less scatter than plots of $S$ calculated from the same data.

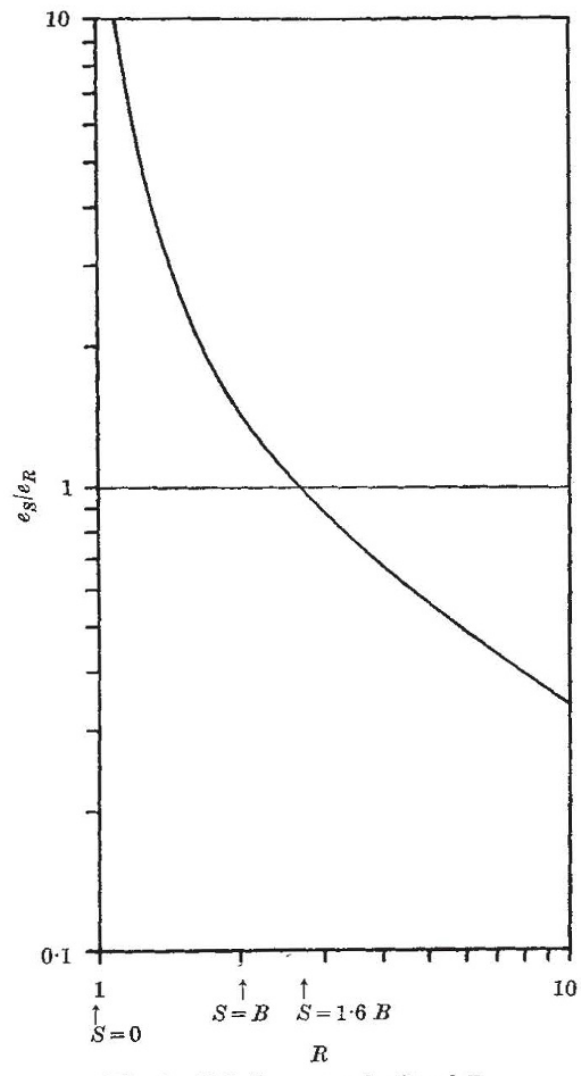

Fig. 1. Relative errors in $S$ and $R$

This work was supported by a grant from the Lowell Technological Institute Research Foundation. I thank K. H. Olson for his advice.

ERANCrs T. WORRELI

Lowell Technological Institute Research Foundation, Lowell, Massachusetts.

\section{GEOLOGY}

\section{An Interglacial Soil at Teindland, Morayshire}

ReCentry a fairly well preserved podsol was found buried beneath glacial deposits at Teindland, Morayshire (map ref. O.S. 299566). Briefly, the section shows at the top a semi-podsol developed in 6-8 $\mathrm{ft}$. of sandy till and outwash gravel overlying a fossil iron podsol developed in glacio-fluvial outwash. The upper part of the buried soil which originally was the organic and leached layers has been transformed to thin bands of black, dark grey and light grey material. This banding has most likely been produced by solifluxion.

The black bands were sampled in September 1963 and found to contain 1.44 per cent organic carbon. A sample submitted to the National Physical Laboratory (reference $\theta$ $N P L$-78) for radiocarbon measurement was dated to $28,140+480$ and -450 years (B.P.), where the uncertainties quoted are derived from one standard deviation of the activity measurement. The age must be regarded as a minimum, since the nature of the sample precluded alkali pretreatment.

Hence the history of the site may be reconstructed as follows: (1) Glaciation (Riss ?) followed by the deposition of glaciofluvial deposits. (2) Soil formation in the above deposits to produce a well-developed iron podsol. (3) Periglacial conditions which caused disturbance and solifluxion of the surface layers. (4) A second period of glaciation (Würm ?) during which the soil was buried with till and outwash. (5) Holocene pedogenesis in the upper part of the Würm deposits. 